\title{
Retour sur « Systèmes techniques de production lithique »
}

Jean-Michel Geneste

\section{(2) OpenEdition}

1 Journals

Édition électronique

URL : https://journals.openedition.org/tc/5068

DOI : $10.4000 /$ tc. 5068

ISSN : 1952-420X

Éditeur

Éditions de l'EHESS

\section{Édition imprimée}

Date de publication : 30 juin 2010

Pagination : 416-418

ISSN : 0248-6016

\section{Référence électronique}

Jean-Michel Geneste, «Retour sur « Systèmes techniques de production lithique » », Techniques \&

Culture [En ligne], 54-55 | 2010, mis en ligne le 30 juin 2013, consulté le 29 septembre 2022. URL :

http://journals.openedition.org/tc/5068 ; DOI : https://doi.org/10.4000/tc.5068 


\section{Retour sur}

\section{« Systèmes techniques de production lithique »}

La question qui se posait au sein des études des productions paléolithiques lorsque l'article qui suit a été écrit, était de savoir dans quelle mesure les systèmes techniques distants de nous de dizaines ou centaines de milliers d'années étaient ou non accessibles en tant que systèmes techniques spécifiques de la préhistoire et comparables à ceux qu'étudie la technologie culturelle de nos contemporains. Cet article témoigne parmi d'autres (Boëda 1991 ; Ploux, Bodu, Karlin 1991) des lectures et interprétations consécutives menant les archéologues à développer une manière originale de traiter des systèmes techniques paléolithiques. Les travaux qui ont alors vu le jour ont clairement confirmé la légitimité d'analyser ces systèmes complexes, fragmentaires et éloignés dans le temps.

L'étude des systèmes techniques préhistoriques à travers les vestiges de la culture matérielle des sociétés du passé lointain et surtout les plus éloignés de nous, doivent plus que jamais se développer sur un ancrage théorique technologique, un recours à des référentiels expérimentaux pluridisciplinaires et à une mise en perspective ethnoarchéologique établissant des référentiels multiples et variés de comparaison.

Les apports de la technologie expérimentale sont fondamentaux et source de perspectives renouvelées aussi bien dans le domaine matériel des pratiques techniques que dans l'élaboration de référentiels critiques et réfutables indispensables pour aborder l'ensemble du domaine de la technologie paléolithique. En ce sens, les programmes de technologie expérimentale des deux dernières décennies n’ont pas seulement livré des résultats sur l'efficacité technique de certains principes de transformation de la matière naturelle, les principes de production d'objets et leur utilisation sur d'autres matériaux, ils ont aussi permis d'estimer que des facteurs souvent discrets, insuffisamment pris en compte, ou inaccessibles du point de vue archéologique, pouvaient jouer un rôle important dans le fonctionnement, l'équilibre et les objectifs mêmes des systèmes (Pétrequin, Pétrequin 1993). 
Certains de ces paramètres se rencontrent tant dans les détails techniques matériels que dans les manières de vivre une réalité technique, de réagir socialement à des productions, que dans un objet technique ou même dans la matière première. Ainsi, le rôle social et la puissance territoriale des sources de matières premières lithiques sont très diversement perçus selon qu'il s'agit de productions qui datent de 500000,50000 ou de 20000 ans, car elles sont encore trop souvent dépendantes de cadres conceptuels propres à l'analyse de ces différentes époques. L'existence même de programmes de technologie expérimentale pluridisciplinaires a fait éclater les limites de certaines classifications, de la périodisation et du cloisonnement méthodologique en œuvre dans la discipline.

De relativement abstraites au départ, ces démarches sont devenues plus réalistes et complexes ensuite. La confrontation des systèmes techniques préhistoriques avec les données ethnoarchéologiques est par ailleurs l'autre tendance qui s'est affirmée depuis l'écriture de cet article (Pétrequin, Pétrequin, 1993). Au-delà du comparatisme ethnologique dont les risques avaient été soulignés à la suite d'André Leroi-Gourhan pour ne citer que lui, le regard actuel porté sur ces systèmes techniques est moins déshumanisé et moins abstrait, la prise en compte de l'importance du contexte social dans l'étude de situations ethnoarchéologiques a nourri à son tour les démarches fonctionnalistes précédentes.

Ce nouveau positionnement disciplinaire ouvre des perspectives et désigne des voies et des explications sociales qui dépassent le seul domaine de l'efficacité et de l'ergonomie productive. Pour une large diversité d'objets archéologiques, les dimensions extrinsèques vont aussitôt être traduites en termes d'avantages et de prestige qui iront bien au-delà des propriétés techniques. Les spécificités territoriales et techniques combinées peuvent transmettre une plus-value sociale à leurs porteurs et propriétaires. Ils sont alors les pourvoyeurs d'un prestige inégalé via une médiation identitaire territoriale (David, 2002).

La culture matérielle et les systèmes techniques préhistoriques sont désormais considérés, à l'image des systèmes techniques actuels, comme des réservoirs de signification sociale (Geneste et al, 2010). Des notions du type de celle de réservoir symbolique, inspirées par les contributions de l'ethnologie et de l'ethnoarchéologie, sont désormais utilisées - même si c'est parfois de façon implicite-par les archéologues pour traiter de questions aussi fondamentales que celle des dynamiques de changement de la culture matérielle.

Photo d'ouverture: Pointe Levallois emmanchée en contexte expérimentale, J.-M. Geneste 2009. 


\section{NOTES ET RÉÉÉRENCES DE L'NTRODUCTION}

Boëda, E. 1991 Approche de la variabilité des systèmes de production lithique des industries du Paléolitique inférieur et moyen: chronique d'une variabilité attendue, Techniques \& culture 17-18 : 37-39.

David, B. 2002 Landscapes, rock-art and the dreaming: An archaeology of pre understanding. Leicester University Press, London.

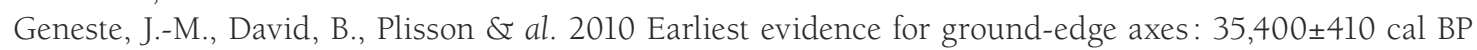
from Jawoyn country, Arnhem Land. Australian Archaeology, December 2010, 71: 66-69.

Pétrequin, P. \& A.-M. Pétrequin 1993 Écologie d’un outil : la hache de pierre en Irian Jaya (Indonésie). CNRSPiaget, Paris.

Ploux, S. Karlin, C. \& P. Bodu 1991 D’une chaîne l'autre: normes et variations dans le débitage laminaire magdalénien, Techniques \& culture 17-18: 81-114. 